\title{
PENGELOMPOKAN DAERAH PENGHASIL BAHAN DASAR TEPUNG KOMPOSIT DI INDONESIA MENGGUNAKAN METODE LATENT CLASS CLUSTER ANALYSIS (LCCA)
}

\author{
Shinta Budiati ${ }^{1}$, Irwan Susanto ${ }^{2}$, dan Supriyadi Wibowo ${ }^{3}$ \\ ${ }^{1}$ Mahasiswa Jurusan Matematika FMIPAUNS \\ ${ }^{2,3}$ Dosen Jurusan Matematika FMIPA UNS
}

\begin{abstract}
Wheat as a base substance of flour, is a source of carbohydrate which is most used for the manufacturing of variety of foodstuffs. Substitution a part of flour with composite flour for manufacturing food will decrease dependency of imported wheat.This research aims to classify the area which produce base substance of composite flour in Indonesia.For this research we will know a group of provinces which become center of production and development target of local resources potency. One way that is used to grouping the object is cluster analysis. In development, there is another grouping technique used, namely Latent Class Cluster Analysis (LCCA).The results show that the selected model from grouping using LCCA is 3groups. The first group is the enough potential area as a production development center. While the second group have the greatest potential area. Meanwhile the last group is the less potentially area.
\end{abstract}

Keywords: Composite Flour, Cluster Analysis, Latent Class Cluster Analysis (LCCA)

\section{Pendahuluan}

Sampai dengan tahun 2013, gandum masih merupakan barang impor. Disamping itu gandum sebagai bahan dasar tepung terigu, merupakan sumber karbohidrat yang paling banyak digunakan untuk pengolahan berbagai bahan makanan. Badan Pusat Statistik ${ }^{[1]}$ menyebutkan, impor komoditas gandum di Indonesia meningkat setiap tahunnya sehingga Indonesia menjadi negara importir gandum kedua terbesar di dunia setelah Mesir. Salah satu cara yang digunakan untuk mengurangi impor gandum bagi Indonesia yang bukan merupakan penghasil gandum yaitu dengan mensubstitusi sebagian tepung terigu dengan non terigu. Menurut Ernie ${ }^{[2]}$ tepung kompositmerupakan tepung campuran antara tepung terigu dengan tepung non terigu.

Dari permasalahan impor gandum tersebut, perlu adanya pengelompokan daerah penghasil bahan dasar tepung komposit tiap provinsi di Indonesia. Dari penelitian ini, dapat diketahui kelompok provinsi yang menjadi sentra produksidan menjadi target pengembangan potensi sumber daya lokal. Salah satu carayang digunakan untuk pengelompokan objek adalah analisis cluster. Analisis cluster merupakan teknik pengelompokan yang didasarkan pada kemiripan objek. Dalam perkembangannya, terdapat teknik pengelompokan lain yang dapat digunakan, yaitu Latent Class Cluster Analysis (LCCA) yang menggunakan konsep probabilitas dalam pengelompokan objek. Analisis ini pertama kali diperkenalkan oleh Lazarfeld dan Henry ${ }^{[4]}$ pada tahun 1968 untuk pengelompokan berdasarkan variabel dikotomus, kemudian diperluas untuk variabel bertipe nominal oleh Goodman ${ }^{[3]}$. Dalam perkembangannya, analisis ini dapat digunakan untuk pengelompokan objek pada variabel kategorik, kontinu, jumlah dan campuran.

Penelitian mengenai pengelompokan menggunakan metode LCCA pernah dilakukan oleh Vermunt and Magidson ${ }^{[6]}$ untuk kasus pengelompokan pasien diabetes dengan 3 variabel kategorik dan juga mengelompokkan pasien kanker prostat dengan model 
campuran, yaitu menggunakan 8 variabel kontinu dan 4 variabel kategorik. Penelitian serupa juga pernah dilakukan oleh Snellman ${ }^{[5]}$ untuk mengelompokkan pasien dengan penyakit pneumonia atau radang paru-paru dengan menggunakan beberapa variabel yang bertipe kategorik. Pada penelitian ini, metode LCCA diterapkan untuk mengelompokkan daerah penghasil bahan dasar tepung komposit di Indonesia.

\section{Metode Penelitian}

Metode yang digunakan dalam penelitian ini adalah studi kasus. Selanjutnya metode LCCAditerapkan pada data yang berpengaruh terhadap potensisumber daya daerah tiap provinsi di Indonesia seperti luas panen, tingkat produktivitas, jumlah produksi dan ketersediaan pabrik penghasil tepung. Data yang digunakan adalah data sekunder yang diperoleh dari Badan Pusat Statistik (Statistik Indonesia Tahun 2012) yang merupakan data komoditi tanaman pangan yang dapat dijadikan bahan dasar tepung komposit seperti jagung, padi,dan ubi.

Adapun langkah-langkah yang dilakukan untuk mengelompokkan daerah dengan menggunakan metode LCCA adalah terlebih dahulu membentuk model LCCA. Secara umum model $L C C A$ pada data dengan variabel-variabel yang memiliki bermacam skala pengukuran dapat dirumuskan dengan persamaan

$$
f\left(\boldsymbol{y}_{h} \mid \boldsymbol{\theta}\right)=\sum_{k=1}^{K} \pi_{k}\left[g\left(\boldsymbol{y}_{h} \mid \boldsymbol{\theta}\right)\right]
$$

dengan $\pi_{k}$ merupakan peluang awal (prior) kelompok ke- $k, \theta$ adalah himpunan parameter, $k$ merupakan banyak kelompok $(k=1,2, \ldots, K)$, dan persamaan $g\left(\boldsymbol{y}_{h} \mid \boldsymbol{\theta}\right)$ merupakan fungsi campuran dari distribusi multinomial untuk tipe data nominal yang didefinisikan

$$
g\left(\boldsymbol{y}_{h} \mid \alpha_{k}\right)=\prod_{i=1}^{Q} \prod_{s=1}^{S}\left(\alpha_{k(i s)}\right)^{y_{h(i s)}}
$$

dan distribusi yang diasumsikan normal untuk tipe data rasio dengan persamaan

$$
g\left(\boldsymbol{y}_{h} \mid \mu_{i k}, \sigma_{i k}^{2}\right)=\frac{1}{2 \pi^{R} / 2 \prod_{\mathrm{i}=1}^{\mathrm{R}} \sigma_{i k}} \exp \left[-\frac{1}{2} \sum_{i=1}^{R} \frac{\left(y_{h i}-\mu_{i k}\right)^{2}}{\sigma_{i k}^{2}}\right] .
$$

Setelah model LCCA terbentuk selanjutnya mengestimasi parameter dengan menggunakan metode Maximum Likelihood Estimation (MLE). Fungsi log likelihood untuk LCCA dengan mensubtitusi Persamaan (2) dan (3) ke dalam Persamaan (1) adalah

$L=\sum_{h=1}^{N} \log \left[\sum_{k=1}^{K} \pi_{k}\left[\prod_{i=1}^{Q} \prod_{s=1}^{S}\left(\alpha_{k(i s)}\right)^{y_{h(i s)}}\right]\left[\frac{1}{2 \pi^{\mathrm{R}} / 2 \prod_{\mathrm{i}=1}^{\mathrm{R}} \sigma_{i k}} \exp \left[-\frac{1}{2} \sum_{\mathrm{i}=1}^{\mathrm{R}} \frac{\left(y_{h i}-\mu_{i k}\right)^{2}}{\sigma_{i k}^{2}}\right]\right]\right.$

dengan $N$ merupakan banyaknya data keseluruhan, $Q$ adalah banyaknya variabel bertipe nominal, $S$ adalah banyaknya kategori pada variabel bertipe nominal dan $R$ adalah banyaknya variabel bertipe rasio.

Fungsi log likelihood tersebut dapat dimaksimumkan dengan metode iterasi Expectation Maximization (EM) yang dilanjutkan dengan metode iterasi Newton Raphson $(N R)$. Menurut Vermunt dan Magidson ${ }^{[7]}$ kedua metode iterasi tersebut digunakan karena masing-masing memiliki kelebihan, yaitu kestabilan dari $E M$ bahkan ketika nilainya jauh dari optimal dan kecepatan estimasi dengan $N R$ ketika nilainya sudah mendekati optimal. 
Dengan diberikan k kelompok awal, proses estimasi pada algoritma $E M$ terdiri dari dua langkah dengan mengambil nilai awal $\boldsymbol{\theta}^{(0)}=\left(\pi_{k}{ }^{(0)}, \alpha_{k(i s)}{ }^{(0)}, \mu_{i k}{ }^{(0)}, \sigma_{i k}{ }^{2(0)}\right)$, yang selanjutnya dilakukan

1. Langkah $E$ (Expectation)

dalam langkah ini dicari $\hat{P}\left(k \mid \boldsymbol{y}_{\boldsymbol{h}}\right)$ berdasarkan data yang diobservasi dari estimasi parameter model yang telah ada. Kemudian dengan $\hat{\pi}_{k}{ }^{(r)}$ merupakan probabilitas prior, dihitung probabilitas posterior untuk setiap kelompok yang dinotasikan dengan

$$
\hat{P}\left(k \mid \boldsymbol{y}_{h}\right)^{(r+1)}=\frac{\widehat{\pi}_{k}^{(r)}\left[g\left(\boldsymbol{y}_{h} \mid \widehat{\boldsymbol{\theta}}\right)^{(r)}\right]}{\sum_{k=1}^{K} \widehat{\pi}_{k}^{(r)}\left[g\left(\boldsymbol{y}_{h} \mid \widehat{\boldsymbol{\theta}}\right)^{(r)}\right]},
$$

2. Langkah $M$ (Maximization)

yaitu menghitung $M L E$ dengan memaksimumkan ekspektasi likelihood menggunakan nilai yang didapat dari Persamaan (5). Estimasi parameter pada setiap kelompoknya adalah

$$
\hat{\pi}_{k}^{(r+1)}=\frac{\sum_{h=1}^{N} \hat{P}\left(k \mid y_{h}\right)^{(r+1)}}{N}
$$

untuk variabel berskala nominal

$$
\hat{\alpha}_{k(i s)}{ }^{(r+1)}=\frac{\sum_{h=1}^{N} y_{h(i s)} \hat{P}\left(k \mid y_{h}\right)^{(r+1)}}{N \widehat{\pi}_{k}^{(r+1)}}
$$

untuk variabel berskala rasio, rataan dari kelompok $\mathrm{k}$

$$
\hat{\mu}_{i k}^{(r+1)}=\frac{\sum_{h=1}^{N} y_{i h} \hat{P}\left(k \mid y_{h}\right)^{(r+1)}}{N \widehat{\pi}_{k}^{(r+1)}}
$$

dan variansi di dalam tiap kelompok

$$
\hat{\sigma}_{i k}^{2(r+1)}=\frac{\sum_{h=1}^{N} \sum_{k=1}^{K}\left(y_{i h}-\widehat{\mu}_{i k}{ }^{(r+1)}\right)^{2} \hat{P}\left(k \mid y_{h}\right)^{(r+1)}}{\sum_{h=1}^{N} \sum_{k=1}^{K} \hat{P}\left(k \mid y_{h}\right)^{(r+1)}},
$$

Kedua langkah ini dilakukan terus menerus hingga mencapai nilai konvergen. Kemudian setelah didapatkan nilai estimasi parameter dari algoritma EM dilanjutkan dengan memasukkan nilai tersebut ke dalam algoritma $N R$ agar nilai estimasi parameter yang didapat lebih optimal. Menurut Vermunt dan Magidson ${ }^{[7]}$ nilai parameter dapat dihitung menggunakan vektor gradien $(g)$ dan inverse dari matriks Hessian $(H)$ yang diperoleh dari iterasi sebelumnya, sehingga algoritma $N R$ dapat dituliskan

$$
\hat{\theta}^{(r+1)}=\hat{\theta}^{(r)}-H^{(r)-1} g^{(r)} .
$$

Setelah didapatkan nilai estimasi parameternya kemudian ditentukan jumlah kelompok dengan melihat nilai Bayesian Information Criterion (BIC) terkecil

$$
B I C_{L L}=-2 L L+\ln (N) M,
$$


dengan $N$ adalah banyaknya data keseluruhan, $M$ menunjukkan jumlah parameter dan $L L$ merupakan nilai log likelihood yang telah optimum.

Model LCCA memiliki asumsi bahwa setiap variabel yang berada dalam satu kelompok haruslah saling bebas. Uji asumsi pada LCCA dapat dilihat dari nilai Bivariate Residual $(B V R)$ yang didefinisikan

$$
B V R=\frac{X^{2}}{d b}=\frac{\sum_{i=1}^{b} \sum_{j=1}^{k} \frac{\left(o_{i j}-E_{i j}\right)^{2}}{E_{i j}}}{d b},
$$

dengan $O_{i j}$ merupakan frekuensi observasi, $E_{i j}=\frac{n_{i} m_{j}}{N}$ merupakan frekuensi harapan dan $d b$ adalah derajat bebas. Pada saat nilai $B V R$ lebih besar dari $\chi_{(\alpha ; d b=(b-1)(k-1)=1)}^{2}$, maka asumsi kebebasan lokal terpenuhi. Apabila asumsi tidak terpenuhi, maka dapat dilakukan penanganan dengan menggunakan direct effect. Menurut Vermunt and Magidson ${ }^{[5]}$ direct effect dilakukan dengan menambahkan gabungan dua variabel yang tidak saling bebas pada model awal $L C C A$ sampai didapatkan nilai $B V R$ yang memenuhi asumsi.

Model yang dipilih perlu diketahui seberapa besar tingkat kelayakannya dengan menggunakan nilai statistik Wald $($ pvalue $<\alpha)$ dan $R^{2}$. Klasikasi objek ke dalam kelompok $k$ didasarkan pada nilai probabilitas posterior yang tertinggi. Setelah diperoleh hasil klasifikasi dapat dideskripsikan karakteristik dari masing-masing daerah di setiap kelompok yang terbentuk.

\section{Hasil Dan Pembahasan}

\subsection{Model $L C C A$}

Data yang digunakan pada penelitian ini adalah data potensi daerah di 33 provinsi di Indonesia untuk komoditi tanaman pangan yang digunakan sebagai bahan dasar tepung komposit seperti jagung, padi dan ubi. Data yang digunakan adalah data sekunder yang diperoleh dari Badan Pusat Statistik ${ }^{[1]}$. Variabel dan tipenya dapat dilihat pada Tabel 1.

Tabel 1. Variabel yang Digunakan Beserta Tipe Variabel

\begin{tabular}{llc}
\hline \multicolumn{1}{c}{ Variabel } & \multicolumn{1}{c}{ Komoditi } & TipeVariabel \\
\hline Luas panen & Jagung, Padi, Ubi & Kontinu \\
Produktivitas & Jagung, Padi, Ubi & Kontinu \\
Produksi & Jagung, Padi, Ubi & Kontinu \\
Ketersediaan Pabrik & Jagung, Padi, Ubi & Nominal \\
\hline
\end{tabular}

Dari hasil analisis data, terlihat bahwa pada provinsi Kepulauan Riau dan DKI Jakarta memiliki luas panen, tingkat produktivitas dan jumlah produksi yang sangat kecil nilainya. Bahkan pada provinsi DKI Jakarta tidak terdapat lahan luas panen untuk komoditi ubi. Hal tersebut dikarenakan provinsi DKI Jakarta merupakan ibukota Indonesia dan Kepulauan Riau merupakan daerah yang memiliki banyak pantai atau pulau, sehingga sangat sulit menemukan lahan untuk menanam komoditi tanaman pangan.

Data pada kedua provinsi tersebut dianggap sebagai influential cases karena memiliki nilai yang terlampau kecil dibandingkan dengan provinsi lainnya, maka dari 33 provinsi yang akan diteliti provinsi Kepulauan Riau dan DKI Jakarta dianggap tidak dapat mewakili populasi sehingga data yang digunakan dalam penelitian ini sebanyak 31 provinsi.

Menurut Vermunt dan Magidson ${ }^{[6]}$, umumnya variabel kontinu (rasio atau interval) pada model $L C C A$ diasumsikan berdistribusi normal. Sehingga dilakukan uji 
asumsi normalitas terhadap data menggunakan uji Shapiro Wilk untuk variabel yang bertipe kontinu : variabel luas panen, tingkat produktivitas dan jumlah produksi.

Dari analisis perhitungan dengan perangkat lunak SPSS, pada Tabel 2 terlihat bahwa asumsi normalitas hanya terpenuhi pada variabel produktivitas jagung dan padi, selain itu variabel tidak berdistribusi normal atau p-value $<0,05$. Sehingga dilakukan transformasi data pada variabel luas panen (jagung, padi, dan ubi), produktivitas (ubi) dan jumlah produksi (jagung, padi dan ubi) dengan transformasi Box-Cox.

Tabel 2. Hasil Uji Normalitas Data Sebelum Ditransformasi

\begin{tabular}{lc}
\hline Variabel & p-value \\
\hline Luas panen jagung & 0,000 \\
Luas panen padi & 0,000 \\
Luas panen ubi & 0,000 \\
Produktivitas jagung & 0,494 \\
Produktivitas padi & 0,366 \\
Produktivitas ubi & 0,004 \\
Produksi jagung & 0,000 \\
Produksi padi & 0,000 \\
Produksi ubi & 0,000 \\
\hline
\end{tabular}

Setelah dilakukan transformasi, semua variabel sudah memenuhi asumsi normalitas atau nilai $\mathrm{p}$-value $>0,05$, seperti yang ditunjukkan dalam Tabel 3 berikut

Tabel 3. Hasil Uji Normalitas Data Setelah Ditransformasi

\begin{tabular}{lc}
\hline Variabel & p-value \\
\hline Luas panen jagung & 0,962 \\
Luas panen padi & 0,183 \\
Luas panen ubi & 0,079 \\
Produktivitas jagung & 0,494 \\
Produktivitas padi & 0,366 \\
Produktivitas ubi & 0,852 \\
Produksi jagung & 0,883 \\
Produksi padi & 0,241 \\
Produksi ubi & 0,116 \\
\hline
\end{tabular}

\subsection{Estimasi Parameter}

Dari data yang digunakan kemudian dibentuk model $L C C A$ dengan $k$ yang berbeda. Secara umum model LCCA untuk $k$ kelompok dituliskan pada Persamaan (1). Misalkan untuk $k=1,2, \ldots, K$, model $L C C A$ dapat dituliskan sebagai berikut

$$
\begin{aligned}
& f\left(\boldsymbol{y}_{h} \mid \boldsymbol{\theta}\right)=\pi_{1}\left[\left[\prod_{i=1}^{3} \prod_{s=1}^{2}\left(\alpha_{1(i s)}\right)^{y_{h(i s)}}\right]\left[\frac{1}{2 \pi^{9 / 2} \prod_{\mathrm{i}=1}^{9} \sigma_{i 1}} \exp \left[-\frac{1}{2} \sum_{\mathrm{i}=1}^{9} \frac{\left(y_{h i}-\mu_{i 1}\right)^{2}}{\sigma_{i 1}^{2}}\right]\right],\right. \\
& f\left(\boldsymbol{y}_{h} \mid \boldsymbol{\theta}\right)=\sum_{k=1}^{2} \pi_{k}\left[\left[\prod_{i=1}^{3} \prod_{s=1}^{2}\left(\alpha_{k(i s)}\right)^{y_{h(i s)}}\right]\left[\frac{1}{2 \pi^{9 / 2} \prod_{\mathrm{i}=1}^{9} \sigma_{i k}} \exp \left[-\frac{1}{2} \sum_{\mathrm{i}=1}^{9} \frac{\left(y_{h i}-\mu_{i k}\right)^{2}}{\sigma_{i k}^{2}}\right]\right],\right.
\end{aligned}
$$




$$
f\left(\boldsymbol{y}_{h} \mid \boldsymbol{\theta}\right)=\sum_{k=1}^{K} \pi_{k}\left[\left[\prod_{i=1}^{3} \prod_{s=1}^{2}\left(\alpha_{k(i s)}\right)^{y_{h(i s)}}\right]\left[\frac{1}{2 \pi^{9 / 2} \prod_{\mathrm{i}=1}^{9} \sigma_{i k}} \exp \left[-\frac{1}{2} \sum_{\mathrm{i}=1}^{9} \frac{\left(y_{h i}-\mu_{i k}\right)^{2}}{\sigma_{i k}^{2}}\right]\right],\right.
$$

Dari hasil perhitungan, diperoleh bahwa semakin besar jumlah $k$ kelompok yang dibentuk, tidak mempengaruhi kesimpulan penentuan dari jumlah kelompok yang akan dipilih. Dalam penelitian ini, sebagai contoh diambil $K=5$. Dari 5 model yang dibentuk akan diestimasi parameter dengan menggunakan algoritma $E M$ dan algoritma $N R$. Setelah didapatkan nilai estimasi parameter yang optimal, kemudian nilai estimasi parameter tersebut disubtitusikan ke Persamaan (4) pada masing-masing model yang dibentuk. Nilai log likelihood yang maksimum dapat dilihat pada Tabel 4.

Tabel 4. Nilai Log Likelihood dan BIC untuk Setiap Model

\begin{tabular}{cccrrr}
\hline Model & Jumlah Kelompok & log likelihood & \multicolumn{1}{c}{ BIC } & Npar & Class.Err. \\
\hline Model 1 & 1-Cluster & $-471,0616$ & 1014,2369 & 21 & 0,0000 \\
Model 2 & 2-Cluster & $-377,3874$ & 902,4362 & 43 & 0,0002 \\
Model 3 & 3-Cluster & $-330,0598$ & 883,3287 & 65 & 0,0032 \\
Model 4 & 4-Cluster & $-303,1717$ & 905,1003 & 87 & 0,0026 \\
Model 5 & 5-Cluster & $-285,9128$ & 946,1302 & 109 & 0,0021 \\
\hline
\end{tabular}

Pada Tabel 4 diketahui bahwa model 3 memiliki nilai $B I C$ terkecil dibandingkan dengan model yang lain yaitu sebesar 883,3287. Dari hasil tersebut, model yang dipilih adalah model dengan 3 kelompok.

\subsection{Uji Asumsi Kebebasan Lokal}

Dari model yang dipilih akan diuji asumsi kebebasan lokal dengan nilai $B V R$ yang dapat dilihat pada Tabel 5.

Tabel 5. Nilai Log Likelihood dan BIC Setelah Dilakukan Penanganan Direct Effect

\begin{tabular}{cccrrc}
\hline Model & log likelihood & \multicolumn{1}{c}{ BIC } & Npar & Class. Err. & Selang BVR \\
\hline 3-Cluster & $-330,0598$ & 883,3287 & 65 & 0,0032 & $0,0000-9,1462$ \\
1 direct effect & $-291,7743$ & 817,0597 & 68 & 0,0032 & $0,0000-8,6978$ \\
2 direct effect & $-254,8144$ & 753,4418 & 71 & 0,0001 & $0,0000-7,5701$ \\
3 direct effect & $-218,6239$ & 691,3628 & 74 & 0,0014 & $0,0000-1,6222$ \\
\hline
\end{tabular}

Diketahui bahwa model dengan 3 kelompok memiliki selang $B V R$ antara 0,0000-9,1462. Oleh karena itu asumsi kebebasan lokal belum terpenuhi, sehingga perlu dilakukan penanganan dengan penambahan direct effect sebanyak 3 kali kedalam model dengan 3 kelompok. Dari penanganan tersebut dapat disimpulkan seluruh pasangan variabel sudah memenuhi asumsi kebebasan lokal dengan selang $B V R$ antara 0,00001,6222 $(B V R<3,84)$. Dari hasil penanganan tersebut,diperoleh nilai log likelihood yang maksimum sebesar -218,6239 dan BIC yang terkecil sebesar 691,3628.

\subsection{Uji Kelayakan Model}

Dari model yang dipilih akan diuji kelayakan model dengan melihat nilai $p$-value dari statistik Wald dan $R^{2}$. Diketahui bahwa nilai $p$-value dari statistik Wald $=0,022 \leq 0,05$ dan nilai $R^{2}$ yang terbesar terletakpada variabel produktivitas ubi yaitu $70,53 \%$. Dari nilai tersebut dapat disimpulkan bahwa secara keseluruhan model ini sudah memenuhi kriteria 
kelayakan dengan karakteristik potensi daerah penghasil bahan dasar tepung komposit diIndonesia dapat dijelaskan oleh variabel produktivitas ubi yaitu sebesar 70,53\%.

\subsection{Klasikasi Daerah}

Banyaknya daerah pada setiap kelompok yang terbentuk diperoleh dari nilai probabilitas dikalikan dengan total sampel, yang hasilnya dapat dilihat pada Tabel 6 .

Tabel 6. Pengelompokan ke dalam Kelompok yang Terbentuk

\begin{tabular}{ccc}
\hline Kelompok & Probabilitas & Banyaknya Daerah \\
\hline 1 & 0,5736 & 18 \\
2 & 0,2291 & 7 \\
3 & 0,1973 & 6 \\
\hline Jumlah & $\mathbf{1 , 0 0 0 0}$ & $\mathbf{3 1}$ \\
\hline
\end{tabular}

Pengelompokan suatu daerah masuk ke dalam kelompok didasarkan pada nilai probabilitas posterior yang maksimum dari kelompok yang terbentuk. Provinsi Aceh, Riau, Jambi, Sumatera Selatan, Bengkulu, Daerah Istimewa Yogyakarta, Banten, Bali, Kalimantan Barat, Kalimantan Selatan, Kalimantan Timur, Sulawesi Tengah, Sulawesi Barat, Maluku, Nusa Tenggara Barat, Sulawesi Utara,dan Gorontalo merupakan daerah yang masuk kelompok 1. Provinsi Sumatera Utara, Sumatera Barat, Lampung, Jawa Barat, Jawa Tengah, Jawa Timur, dan Sulawesi Selatan merupakan anggota yang termasuk kelompok 2. Provinsi Bangka Belitung, Nusa Tenggara Timur, Kalimantan Tengah, Maluku Utara, Papua Barat, dan Papua termasuk kelompok 3.

\subsection{Karakteristik Kelompok yang Terbentuk}

Secara umum karakteristik yang terbentuk dari masing-masing kelompok dapat dilihat pada Tabel 7.

Tabel 7. Rata-rata Beberapa Variabel pada Setiap Kelompok yang Terbentuk

\begin{tabular}{llrrr}
\hline \multirow{2}{*}{ Variabel } & \multirow{2}{*}{ Komoditi } & \multicolumn{3}{c}{ Rata-rata } \\
\cline { 3 - 5 } & & Kelompok 1 & Kelompok 2 & Kelompok 3 \\
\hline Luas panen (ha) & Jagung & 40012,83 & 410830,57 & 44700,17 \\
& Padi & 244531,94 & 1190138,43 & 78164,63 \\
Produktivitas (kuintal/ha) & Jagung & 11195,78 & 141131,00 & 28734,33 \\
& Padi & 36,8183 & 53,6171 & 22,6550 \\
\multirow{2}{*}{ Produksi (ton) } & Ubi & 144,8739 & 52,1086 & 33,1550 \\
& Jagung & 161472,83 & 2023705,43 & 94975,83 \\
\multirow{2}{*}{ Pabrik } & Padi & 1076737,67 & 6420271,14 & 237164,83 \\
& Ubi & 158551,67 & 3092583,71 & 288042,67 \\
& Jagung & tidak ada & ada & tidak ada \\
& Padi & tidak ada & ada & tidak ada \\
& Ubi & ada & ada & tidak ada \\
\hline
\end{tabular}

Dari hasil pengelompokan dengan $L C C A$ dibuat pemetaan daerah sesuai dengan tingkat potensinya yang ditampilkan dalam Gambar 1. 


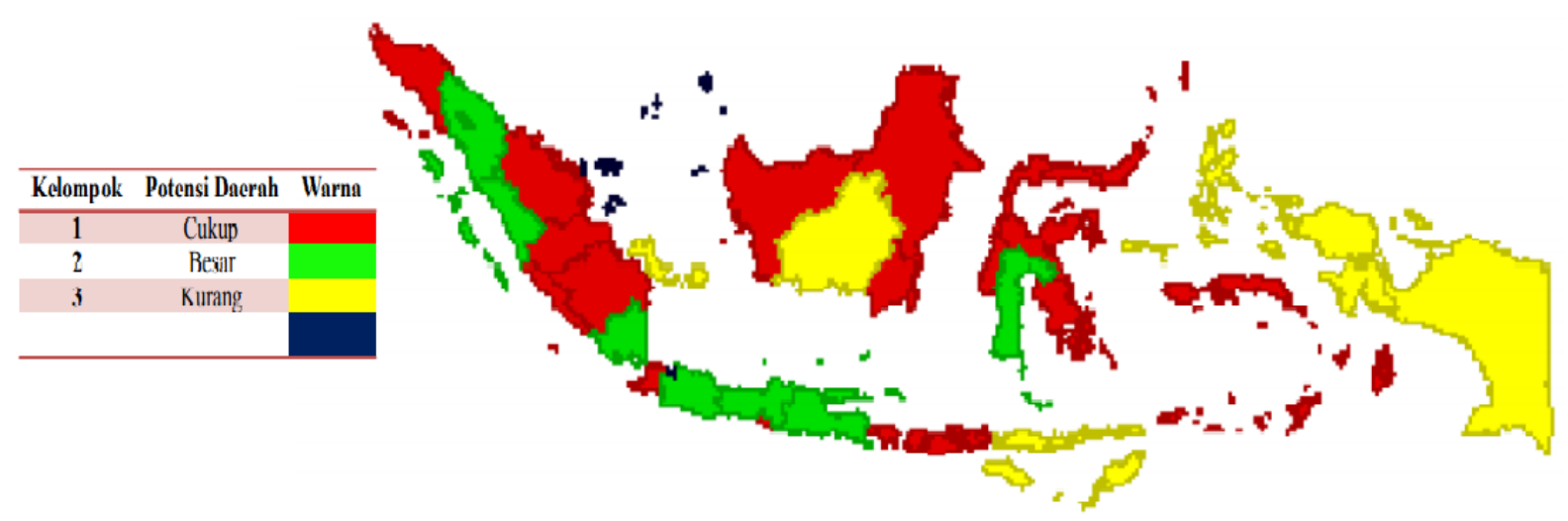

Gambar 1. Pemetaan Potensi Daerah Setiap Provinsi di Indonesia

\section{Kesimpulan}

Hasil penelitian menunjukkan bahwa pengelompokan daerah penghasil bahan dasar tepung komposit di Indonesia dengan menggunakan metode $L C C A$ dipilih model dengan 3 kelompok. Kelompok 1 merupakan daerah yang cukupberpotensi, kelompok 2 merupakan daerah yang besar potensinya dan kelompok 3 merupakan daerah yang kurang berpotensi untuk dijadikan daerah pengembangan sentra produksi.

\section{Ucapan Terima Kasih}

Penulisan artikel ini tidak lepas dari bantuan beberapa pihak, oleh karenaitu penulis ingin mengucapkan terima kasih kepada PT. Indofood Sukses Makmur Tbk dalam program Indofood Riset Nugraha 2013 yang telah memberikan hibah dana penelitian untuk mendukung jalannya penelitian ini.

\section{DAFTAR PUSTAKA}

1. Badan Pusat Statistik, Statistik Indonesia 2012, Badan Pusat Statistik, Jakarta, 2012.

2. Ernie, A.B., Teknologi Pengolahan Singkong. Makalah pada Seminar Nasional Peningkatan Nilai Tambah Singkong, 10 Oktober 1989. Universitas Padjajaran, Bandung

3. Goodman, L.A. Exploratory Latent Structure Analysis Using Both Identifiable and Unidentifiable Models, Biometrika, 1974, 61: 215-231.

4. Lazarsfeld, P. F., and Henry, N. W., Latent Structure Analysis, Houghton Mifflin, Boston, 1968.

5. Snellman, M., Case Definition of Pneumococcal Pneumonia - a Latent Class Analysis Approach, Department of Vaccines, Helsinki, 2008.

6. Vermunt, J. K. and J. Magidson, Applied Latent Class Analysis, Chapter 3. Latent Class Cluster Analysis, Cambridge University Press, New York, 2002.

7. Vermunt, J. K. and J. Magidson, Technical Guide for Latent GOLD 4.0: Basic and Advanced. MA: Statistical Innovations, Inc., Belmont, 2005. 